\title{
Jorge Amado, Pablo Neruda e Nicolás Guillén: História da Literatura, histórias de recepção
}

\author{
Jorge Amado, Pablo Neruda and Nicolás Guillén: \\ Literature History and stories of reception
}

\author{
MÁRCIA Rios DA SiLVA \\ Universidade do Estado da Bahia
}

D

\begin{abstract}
Resumo: Neste artigo, propõe-se uma reflexão acerca da trajetória intelectual e literária de Jorge Amado, Pablo Neruda e Nicolás Guillén, tomada como uma dimensão altamente relevante na construção de histórias de recepção, mas ignoradas pela História da literatura. Como intelectuais de esquerda, comprometidos com as questões sociais do seu tempo, esses escritores tornam-se referência em seus países, e no exterior, na defesa da democracia e contra os regimes ditatoriais. Aproximados pela atuação na esfera pública e na vida cultural e pela consagração extraordinária de público, expandiram significativamente a recepção de suas produções literárias, por várias gerações de leitores, o que impõe pensar o engajamento político (SARTRE, 2004) como potência na formação de público. Essa discussão busca apoio nos estudos de recepção (JAUSS, 2009), histórias de literatura (MOREIRA, 2002; OLINTO, 2002) e escrita da história (BURKE, 1992).
\end{abstract}

Palavras-chave: História da literatura; Recepção; Jorge Amado; Pablo Neruda; Nicolás Guillén

\begin{abstract}
The article aims at proposing a reflection about the intelectual and literary pathways of Jorge Amado, Pablo Neruda and Nicolás Guillén taken as a highly relevant dimension in the construction of stories of reception but ignored by Literature History. Being leftist intellectuals, committed with the social issues of their times, these writers became reference in their countries and abroad as being in favor of democracy and against dictatorial regimes. They were brought together by their public attitude as well as in their intelectual lives and were extraordinarily applauded by the people in general. As a result, they expanded significantly the reception of their literary production throughout several generations of readers which leads to think of their political engagement (SARTRE, 2004) as a powerful tool in formation of an audience. The discussion in this article seeks support in the theory of reception (JAUSS, 2009), stories of literature (MOREIRA, 2002; OLINTO, 2002) and historical writing (BURKE, 1992).
\end{abstract}

Keywords: stories of literature; Reception; Jorge Amado; Pablo Neruda; Nicolás Guillén.

$\mathrm{Na}$ vasta e difusa comunidade latino-americana de leitores, constituída ao longo do século $\mathrm{XX}$, os escritores Jorge Amado, Nicolás Guillén e Pablo Neruda selaram incontestavelmente uma consagração de público, ao longo de suas carreiras, para as quais muito contribuiu a inserção na militância política de esquerda. Amado, Guillén e Neruda são agentes de histórias de recepção de público, as quais escaparam aos compêndios de História da Literatura, campo disciplinar que se orientou, majoritariamente, pela perspectiva diacrônica, centrada na narrativa dos acontecimentos, tendo por foco o autor e as obras literárias.

Se é extensa essa recepção de público, férteis se tornam as narrativas produzidas por seus leitores e admiradores, participantes ou protagonistas de inúmeros acontecimentos que expõem a força da literatura. Algumas cenas pontuais sintetizam a dimensão de uma recepção que extrapolou o campo literário, instigando uma interpretação dos acontecimentos que contemple as articulações engendradas por esses escritores com instâncias de reconhecimento e de legitimação. 
CENA 1 - É verão na Bahia, ano de 2015. Uma jovem turista chega à Fundação Casa de Jorge Amado, localizada no Pelourinho, em Salvador, e procura pela escritora Myriam Fraga, diretora-executiva da casa à época, para entregar-lhe um exemplar do romance Seara vermelha (1946), traduzido para o esloveno ${ }^{1}$. Tomada de emoção e falando bem o português, a leitora se diz orgulhosa com aquela doação ao acervo da Fundação, pelo fato de Jorge Amado ter sido traduzido na língua de sua nação, a Eslovênia, um pequeno país do Leste Europeu que passou pela experiência do comunismo.

Cena 2 - 1973, golpe militar e queda de Salvador Allende, no Chile, morte de Pablo Neruda. No enterro do poeta, marcado pela comoção, diante de tanta dor e revolta, choro, flores, acompanhada por um coro: "Camarada Pablo Neruda, presente, agora e sempre! Povo chileno, presente, agora e sempre! Allende, presente, agora e sempre! Pablo Neruda, presente, agora e sempre! Viva o Partido Comunista"2. Essa comoção sucedeu ao velório de Neruda em sua casa, a La Chascona, destruída pelos militares, onde o poeta foi velado.

Cena 3 - Em outubro de 1967, na Plaza de la Revolución “José Martí”, em Havana, Nicolás Guillén declama, emocionado, para mais de um milhão de cubanos, o extenso poema "Che comandante", em uma solene homenagem a Che Guevara, assassinado nas terras da Bolívia (ORTIZ, 1998) ${ }^{3}$. Os primeiros versos para saudar o herói, o guerrilheiro da latino-américa, exaltam a força de uma luta, expressam a crença em um projeto humanitário, a despeito da violência dos ditadores: "No por callado eres silencio. Y no porque te quemen, porque te disimulen bajo tierra, porque te escondan en cementerio, bosques, páramos, van a impedir que te encontremos Che Comandante, amigo".

Dessas cenas, merece destaque o vigor das palavras atravessando os relatos, em diferentes momentos e contextos, confirmando o poder simbólico da literatura. São acontecimentos que expõem a forte presença de uma comunidade anônima de leitores e admiradores, protagonistas de histórias ignoradas pela tradição da historiografia literária, assentada na catalogação de autores e obras supostamente representativos de uma nação. Muitas histórias narradas, envolvendo o público leitor de Jorge Amado, Pablo Neruda e Nicolás Guillén, ao tempo em que atestam uma admiração, confirmam

\footnotetext{
Essa cena, presenciada pela autora deste texto, ocorreu em janeiro de 2015 na Fundação, onde está guardado o acervo pessoal do escritor.

2 Vídeo Funeral de Pablo Neruda 1973. mp4. Disponível em: <https:/ www.youtube.com/watch? $=x F 7 \mathrm{~s} 8 \mathrm{CM}-\mathrm{dTY}>$. Acesso em: 01 maio 2017.

3 Outros poemas de Guillén lhe são dedicados, dentre eles, "Guitarra em duelo mayor", "Lectura de Domingo" e "Che Guevara".
}

uma recepção de público surpreendente, construída por meios e mediações que extrapolam o campo estritamente literário.

Destaque-se que a noção de público, uma grande abstração, é aqui entendida como a apresentada por Néstor García Canclini (2014), que cuida de fazer a seguinte ressalva: a de não ser tomada "como um conjunto homogêneo e de comportamentos constantes" (2014, p. 150).

O que se denomina público, a rigor, é uma soma de setores que pertencem a estratos econômicos e educativos diversos, com hábitos de consumo cultural e disponibilidade diferentes para relacionarse com os bens oferecidos no mercado. Sobretudo nas sociedades complexas, em que a oferta cultural é muito heterogênea, coexistem vários estilos de recepção e compreensão, formados em relações díspares com bens procedentes de tradições cultas, populares e massivas. Essa heterogeneidade se acentua nas sociedades latino-americanas pela convivência com temporalidades distintas (CANCLINI, 2014, p. 150).

Com relação a Neruda, Guillén e Amado, a esfera política e diferentes meios de comunicação tiveram um papel fundamental para a divulgação da literatura que produziram e a conquista de um público heterogêneo. Para se entender tal alcance, não se pode desprezar os processos de internacionalização de suas carreiras literárias. Como todo fenômeno histórico, as manifestações de recepção de público expõem apropriações e interpretações variadas, e divergentes, da literatura desses escritores, muitas vezes distanciadas de uma concepção do literário elaborada pela tradição culta e letrada. Deflagradas em diferentes contextos socioculturais, as manifestações se apresentam como produções discursivas múltiplas, difusas. Consequentemente, na escrita de histórias de recepção deve ser enfrentada a sua dimensão fragmentária, descontínua das narrativas, sem pretensão de abrangência e totalidade.

No âmbito dos estudos literários, particularmente em relação ao campo da história da literatura, já há algum tempo se constata o declínio de uma perspectiva única e universal, herança do século XVIII, que norteou a escrita dessa história, notadamente diacrônica e centrada no inventário de obras e autores tidos como os mais representativos pelo campo literário erudito, sem que fosse feita uma análise e interpretação do funcionamento das estruturas - instituições responsáveis pelo circuito de produção, circulação e consumo. Nos trabalhos de historiografia literária, pode-se constatar que, ao se fazerem as sínteses de períodos literários, sempre se privilegiou as obras, os autores, inseridos em uma cronologia, dispensando a dimensão recepcional das produções. 
Ao investir na imanência do texto, particularmente com o formalismo russo, o new criticism e o estruturalismo francês, a crítica literária teve um papel fundamental no questionamento de uma escrita da história da literatura que optou pelo primado da diacronia. Tal crítica torna-se decisiva, no século XX, para a consolidação do campo literário erudito, em seu ideal de autonomia da literatura, na busca de uma conceituação, apesar da imprecisão que sempre acompanhou a noção de literário, por ser histórica e variável.

Segundo Maria Eunice Moreira, apesar da perda do prestígio da historiografia literária, que teve seu apogeu no século XIX, a história da literatura demonstra alguns momentos de recuperação no século XX, com o formalismo russo, a estética da recepção e a nova História, por reconhecerem as mutações temporais dos produtos literários (MOREIRA, 2002). Ainda que os formalistas russos tenham investido com vigor no estudo imanente do texto - o que contribuiu para uma renovação da história da literatura -, os trabalhos de Tinianov não perdem de vista o sentido histórico dos textos literários. Afirma a autora, interpretando as reflexões de Tinianov acerca dos estudos sobre literatura:

A noção fundamental que rege uma história da literatura é a de substituição de sistemas, competindo, pois, à história da literatura descrever as transformações dos valores literários no curso do tempo, estudando o desenvolvimento da consciência estética, que implica apelar para elementos de ordem social, ou seja, as atitudes das épocas para com a arte literária (MOREIRA, 2002, p. 126).

Em relação à estética da recepção, que desponta nos anos 1960, a autora ressalta a contribuição significativa de Hans Robert Jauss, não só por deslocar o interesse de estudo - saindo do pólo da produção, o do texto, para o da recepção, o do leitor -, bem como por desfazer "a ilusão da reconstrução do passado, tal como ele foi (a ilusão positivista), pois o passado pode estar submetido a interesses, conjunturas ou situações particulares, que o transformam em construção, ou seja, em pura ficção" (MOREIRA, 2002, p.127). A pesquisadora ressalta a contribuição inovadora de Roland Barthes. Com esse semiólogo, a história da literatura é pensada como uma história do conceito da literatura, não mais fundamentada "nas individualidades que ela reúne (os autores e as obras), mas é considerada a partir do nível da história, daquilo que ele define como a função literária, que envolve relações de ordem de produção, comunicação e consumo" (MOREIRA, 2002, p. 126-127).

O último dos três momentos de recuperação da história, com a estética da recepção, tem uma contribuição destacada por Maria Eunice Moreira, que estaria nas questões colocadas por Hans Ulrich Gumbrecht, que postulou as condições para o aparecimento da história da literatura: "um novo conceito de História", que é abalado enquanto discurso abrangente e totalizante, assumindo-se fragmentária e parcial, o que reverbera nos conceitos de literatura e de histórias da literatura, plurais, portanto. Com isso, muda-se a concepção de história e de literatura:

Os textos literários, que constituem o objeto das histórias literárias, passam a ser entendidos como itens interpretados e avaliados, e não dados objetivos. A história da literatura transforma-se numa construção de um historiador, que, assumindo a posição de narrador, constrói um relato, não do que aconteceu, mas do sentido que ele atribui a um determinado conjunto literário (MOREIRA, 2002, p. 128).

Com Hans Robert Jauss (1994), a hegemonia do estudo imanente é questionada, quando indaga, em seus debates, acerca da experiência estética, como atividade, em sua dimensão produtora, receptiva e comunicativa (cf. JAUSS, 1994). Jauss aponta, assim, para a reescrita da história da literatura, a partir das histórias de leituras, contingentes, variáveis, porque são historicamente produzidas.

Por tal perspectiva, a historiografia literária, como um grande relato legitimador de obras, autores e nacionalidades, é posta em xeque. Desse modo, Jauss pensa as relações concretas entre literatura e vida, entre obra e "horizonte de expectativas do leitor" (cf. JAUSS, 1994). Contudo, a despeito do acento dado ao leitor "real", ao que efetiva as leituras, o pólo da recepção continuará sendo menosprezado nos estudos literários. Antoine Compagnon (2003) ressalta que se encontra com os historiadores o interesse inicial pela história do livro e da leitura, e tais estudos delinearam um campo disciplinar que passa a ser conhecido como Sociologia da Leitura.

De acordo com Heidrun Olinto (2002), os estudos de recepção não ganharam espaço dada a emergência, já nos anos 1970, de novas formas de escrita da história e de experimentos historiográficos, que privilegiam, inclusive, a descontinuidade temporal. Ao indagar sobre as motivações para a escrita de histórias de literatura hoje, o que confirma o declínio de uma história única e com pretensões universalizantes, a autora considera que a resposta se torna ainda mais complicada por ser difícil dizer "o que é literatura" (cf. OLINTO, 2002).

Jauss, por sua vez, se trouxe uma provocação extraordinária aos estudos literários, ao colocar no centro do debate a figura do leitor, apontou o impasse metodológico para se escrever histórias de literatura tomando como ponto de partida o universo dos leitores, seu horizonte de expectativas, bem como a noção de passado, cara ao historiador (cf. JAUSS, 1994). Nesse sentido, a 
história de recepção expõe as articulações do literário com um campo maior. Se a escrita da história da literatura é desafiada a lidar com a temporalidade, a abrir mão de uma sequência cronológica linear e da pretensão totalizadora, não se deve ignorar a estrutura dos acontecimentos, na qual se pode proceder às interpretações dos "fatos" históricos, o que exige extrapolar a esfera literária para entender as histórias de recepção.

Ao discutir o retorno da narrativa dos acontecimentos nos trabalhos historiográficos, Peter Burke (1992) apresenta, em um instigante ensaio, uma contribuição inestimável para a escrita de histórias de recepção, uma vez que estas também devem enfrentar duas questões: narrar e interpretar os acontecimentos. No ensaio, originalmente publicado em 1991, em edição inglesa, Burke ressalta que se assiste, no século $\mathrm{XX}$, ao renascimento da narrativa histórica, que esteve desvalorizada com a emergência da "história estrutural", associada à "escola dos Annales". A questão, ressalte-se, não reside em aderir ou não à narrativa, mas se encontra no modelo narrativo empregado, visto que "as velhas formas são inadequadas para os nossos propósitos" (BURKE, 1992, p. 337).

Burke situa o tema da narrativa histórica em torno de dois debates que se fizeram candentes no século XX, particularmente após os trabalhos da "escola dos Annales". Para esse pensador, o desafio dos historiadores é o de superar a oposição "história dos acontecimentos" ou "história das estruturas", até porque, no seu entendimento, é difícil distinguir os acontecimentos das estruturas. Boa parte de uma produção historiográfica denominada de estrutural veio a ser questionada por proceder a análises estáticas, desistoricizadas, ressalta Burke. Por isso, o historiador propõe uma relação dialética, em que acontecimento e estrutura sejam articulados em uma explicação na escrita da história. Nesse sentido, sugere aos historiadores atenção especial às narrativas literárias, pelas soluções encontradas pelos romancistas em suas tramas, o que pode lhes servir de inspiração para enfrentar os problemas da escrita, alguns, comuns aos historiadores.

Em primeiro lugar, contra o risco da interpretação única no trabalho historiográfico, um dos problemas, Burke propõe a prática da heteroglossia, encontrada em romances que apresentam pontos de vista distintos, diferentes vozes - através dos personagens e narrador -, expondo tensões, conflitos de interesses e de interpretação entre os protagonistas das tramas. "Tal expediente

\footnotetext{
4 Segundo Peter Burke (1992), o trabalho dos historiadores passa por dois momentos de ataque: o primeiro, situado no Iluminismo, reside na crítica à hipótese de que a escrita da história deva ser uma narrativa dos acontecimentos; o segundo situa-se no início do século XX, com a "escola dos Annales" - com Lucien Febvre, Fernand Braudel e outros -, ao se postular que, em vez de narrar os acontecimentos, dever-se-ia analisar as estruturas. Esse segundo momento está marcado pelos debates iniciados nos anos 1960, nos Estados Unidos.
}

permitiria uma interpretação do conflito em termos de um conflito de interpretações" (BURKE, 1992, p. 336). Em segundo lugar, se o trabalho dos historiadores "não reproduz 'o que realmente aconteceu", mas "representa um ponto de vista particular", é fundamental "encontrar um modo de se tornarem visíveis em sua narrativa, não de auto-indulgência, mas advertindo o leitor de que eles não são oniscientes ou imparciais e que outras interpretações, além das suas, são possíveis" (BURKE, 1992, p. 337) 5 .

Em terceiro lugar, deve-se buscar um novo tipo de narrativa - as antigas não respondem mais "às demandas dos historiadores estruturais, ao mesmo tempo em que apresenta um sentido melhor do fluxo do tempo do que em geral o fazem suas análises" (BURKE, 1992, p. 338). Trata-se, assim, de "densificar" a narrativa

para lidar não apenas com a seqüência dos acontecimentos e das intenções conscientes dos atores nesses acontecimentos, mas também com as estruturas - instituições, modos de pensar etc. - e se elas atuam como um freio ou um acelerador para os acontecimentos. Como seria uma narrativa desse tipo? (BURKE, 1992, p. 339) ${ }^{6}$.

Os desafios postos à escrita da história estendem-se à escrita de histórias de recepção de público. Os diferentes modos de recepção produzidos pelos leitores e fãs sinalizam formas distintas de pensamento e sensibilidade, uma heterogeneidade de pontos de vistas dos sujeitos da recepção, apontando, portanto, para múltiplos caminhos na escrita das histórias. Com isso, a renovação da escrita de histórias de literatura encontra um solo fértil no pólo da recepção, pela pluralidade de narrativas produzidas pelo público receptor, pelos surpreendentes e imprevisíveis modos de ler e atribuir sentidos e pela compreensão que expressam acerca da literatura. Assim, torna-se possível conjugar as narrativas dos acontecimentos vivenciados pelos protagonistas, escritores, receptores, agentes e mediadores culturais, com as interpretações de tais acontecimentos e das estruturas. Nesse sentido, os estudos de recepção favorecem deslocamentos investigativos, provocados pelas inevitáveis articulações da esfera literária com o que lhe é lateral ou extraliterário.

Pensar sobre histórias de literatura protagonizadas pelos leitores e fãs de Jorge Amado, Pablo Neruda e

\footnotetext{
Ao encontrar diferentes modos de se estruturar a narrativa nos romances, Burke sugere que na narrativa histórica "fechos alternativos tornam a obra mais 'aberta', no sentido de encorajar os leitores a chegarem às suas próprias conclusões". (BURKE, 1992, p. 339).

6 No sentido dado por Burke a "densificar" a narrativa, há uma alusão à expressão "descrição densa", elaborada por Clifford Geertz, que vem a ser uma descrição "precisa e concreta de práticas ou acontecimentos particulares", quando da interpretação de uma cultura estrangeira (BURKE, 1992, p. 339).
} 
Nicolás Guillén torna-se inevitável, quando se constata o êxito de público ao longo de suas carreiras literárias. A eleição desses escritores está assentada na constatação de que suas experiências literárias guardam pontos em comum, marcando um diferencial no campo literário brasileiro e latino-americano. Como intelectuais de esquerda e ativistas políticos, engajados com as questões sociais de seu tempo, Amado, Neruda e Guillén, além de serem "fenômenos" de recepção de público, tornaram-se referência em seus países, e no exterior, na defesa da democracia e contra os regimes ditatoriais na América Latina. Aproximados pela recepção e consagração extraordinárias, reverberaram a crença em uma sociedade igualitária, ao exporem os processos históricos de exclusão. De modo significativo, expandiram a recepção de suas produções literárias, por várias gerações de leitores, atestando a força da palavra na fabulação de um "povo" (cf. DELEUZE, 2004).

Para se entender o alcance dessa popularidade, e o modo pelo qual tais histórias foram construídas, importa contemplar a atuação pública deles, significativa em suas longas trajetórias, marcando o imbricamento da esfera literária com a extraliterária. Filiados ao Partido Comunista, tiveram uma atuação vigorosa na vida pública, alcançando um reconhecimento, atestado por honrarias, prêmios e condecorações, por frações numerosas de leitores e admiradores e de instâncias consagradoras de legitimação - muitas, inclusive, fora do campo literário -, em diferentes países, sobretudo naqueles de regime socialista.

Ao longo desse percurso, Amado, Neruda e Guillén acumularam um capital simbólico valioso, o que lhes permitiu circular em diferentes instâncias do poder, expondo, assim, a ilusão acerca de uma autonomia literária pregada pelos puristas da arte. Nos livros de memória que escreveram - Amado, Navegação de cabotagem (1993), Neruda, Confesso que vivi (1977) e Guillén, Paginas vueltas (1982) - tem-se o testemunho do valor da literatura no redimensionamento dos homens. Como intelectuais de esquerda, eles produziram uma literatura engajada, na perspectiva sartriana, qual seja, a de marcar um posicionamento político, pelo entendimento de que um intelectual não pode, pelo compromisso com o seu tempo, manter-se em uma redoma, permanecer alheio à realidade social.

Em seu livro Que é literatura?, publicado em 1947, Jean-Paul Sartre indaga sobre a função da literatura no contexto do pós-guerra. Ao perguntar o que é escrever?, Por que escrever?, Para quem se escreve?, Sartre declara uma cobrança acerca do engajamento político da comunidade artística e intelectual, que deve se posicionar frente ao mundo, como em um combate. Isso não significa um posicionamento partidário, como havia sido imposto pela política cultural de Stálin. Em seus questionamentos, Sartre traduz um contexto histórico atravessado por problemas sociais seculares, no qual persiste uma disputa pela manutenção de privilégios da parte dos países colonizadores.

Portanto, considerando o contexto histórico, político e cultural contemporâneo, marcado pelo fim das utopias, pelo deslocamento do papel do intelectual moderno (cf. MARGATO, 2004), impõe-se pensar o legado deixado por esses escritores para a cultura de seus países. Em suas viagens pela América Latina e por distintos países, Amado, Neruda e Guillén vão ampliando o entendimento dos processos de colonização e das desigualdades sociais, de questões políticas e culturais do continente americano, deflagrando uma luta incansável pelos direitos humanos. Nesse sentido, contribuem para a consolidação de uma mentalidade americana e validação de um sentimento de americanidade, num enfrentamento à colonialidade do poder imperial, que se mantém, afirma Mignolo (1996), mesmo após a independência dos países colonizados.

Nas viagens, Amado, Neruda e Guillén estabeleceram vínculos intelectuais e de amizade com outros escritores, artistas e intelectuais. Na defesa dos povos oprimidos, partilharam com um público ampliado um "canto geral" - pelas temáticas e questões vazadas em suas produções literárias, de extração acentuadamente popular. Desse modo, expuseram a luta de classes, pregaram ideais e disseminaram valores culturais construídos na contramão do pensamento hegemônico, imposto pelo Ocidente. Ao alargarem a compreensão desse campo de luta, indagaram sobre o papel da arte e da literatura, apostando na sua força em denunciar as mazelas, bem como em aproximar os homens na construção de uma ética que assegurasse o bem comum.

Em 1933, quando conhece García Lorca na Espanha, Neruda havia publicado 20 poemas de amor e uma canção desesperada, produção que, em sua avaliação, extravasava um "subjetivismo melancólico". Em 1936, começa a guerra civil espanhola, e Lorca é assassinado. Regressa em 1937 da Espanha para o Chile, e a experiência dolorosa que viveu, com os horrores da guerra, o leva a escrever Canto general na casa de Isla Negra. Em seu livro de memórias Confesso que vivi, o poeta declara: "O contato com a Espanha tinha me fortificado e amadurecido. As horas amargas de minha poesia deviam terminar." (NERUDA, 1977, p. 139). E questiona o papel da poesia: "Pode ela servir aos nossos semelhantes? Pode acompanhar as lutas dos homens?". (NERUDA, 1977, p. 139).

Com essas indagações, o poeta chileno busca compreender o seu estar no mundo, pela consciência do papel do intelectual, o que torna imperativo escrever 
o "canto general", vertendo-o em livro, publicado inicialmente no México em 1950 - com 03 edições clandestinas no Chile, bancadas pelo Partido Comunista chileno (cf. COSTA, 2007) -, e na França, em 1954. Com o mandato de senador cassado em 1948, é vetada a publicação de Canto general. Contra esse veto, a Sociedade de Escritores do Chile e o Sindicato de Escritores reivindicam, em uma homenagem a Neruda, em 1951, em Santiago, a sua publicação (NERUDA, 1977, p. 354). Ainda em 1950, o livro é editado em muitos países: "Novas edições nos EUA, China, Tchecoslováquia, Polônia, União Soviética (250.000 exemplares), Suécia, Romênia, Índia, Palestina e Síria" (NERUDA, 1977, p.355). Ao enfrentarem regimes totalitários, muitos escritores sofreram punição ou condenação, viram seus livros serem proibidos de circular em seus países. Tal cerceamento o que o levou ao exílio, como ocorreu também com Amado e Guillén.

Nos anos 1940, em um contexto de guerras, ditaduras, conflitos e reivindicações políticas de diferentes segmentos sociais, fica acentuado, em âmbito internacional, o papel dos intelectuais, não lhes sendo permitido ausentar-se dos debates, nem se absterem de tomar posição ou partido. Assim, artistas, intelectuais e escritores de diferentes nações, destacando-se uma comunidade internacional de intelectuais e artistas negros, irmanam-se na luta contra as injustiças sociais, a miséria no mundo e militam pela descolonização dos países africanos, nos movimentos pró-independência. A comunidade negra vai ter como inspiração para a luta, dentre tantos movimentos de resistência e pela liberdade, a força política e estética do Black Renaissance, ou Harlem Renaissance, quando o canto do poeta negro norte-americano Langston Hughes circulou pelas Américas e atravessou o Atlântico, reverberando em uma extensa comunidade de leitores e admiradores.

Nicolás Guillén, cuja poesia está marcada por traços da vanguarda e pelas questões raciais, tematiza em seu canto os preconceitos e processos de discriminação. Como ressaltam os pesquisadores de sua produção literária, o compromisso de Guillén com o vanguardismo hispano-americano não inviabilizou o encontro da poesia com o son, gênero musical afrocubano, desqualificado pela elite do país. Muitos poemas seus vão ser largamente conhecidos por terem sido musicados, principalmente pelo cantor cubano Pablo Milanés, com um inestimável alcance popular, ultrapassando as fronteiras da ilha. A respeito do traço inovador na sua poesia, Rodriguez Rivera faz a seguinte apreciação: “(...) Los Motivos de son proponen así, un ritmo inédito em nuestra lírica, un ritmo escandaloso e inesperado que, precisamente, era el ritmo del pueblo." (RIVERA, 1982, p. 68, apud Godoy, 2002, p. 1). Afirma Elena Godoy: a experimentação rítmica em Motivos de son procurou resgatar a profunda dívida com a música popular cubana, fazendo com que esses breves poemas se apresentassem como uma maneira alegre e um tanto irresponsável de fazer o costumbrismo (GODOY, 2002, p. 1)

$\mathrm{Na}$ produção literária de Nicolás Guillén, o mais aclamado escritor cubano depois de José Martí, conhecido como o "poeta nacional de Cuba", o "poeta da musicalidade negra", as questões étnico-raciais ganham destaque e categoria no âmbito da língua castelhana. Será o grande combatente na defesa da ilha cubana, que tem uma expressiva população afetada pela experiências traumáticas da colonização, com o domínio espanhol, seguido do controle pelo imperialismo norte-americano.

No trânsito por Portugal nos anos 1940, Jorge Amado estabelece relações de amizade com escritores, artistas e intelectuais africanos, alguns deles, da Casa dos Estudantes do Império, em Lisboa, como Agostinho Neto e a poeta moçambicana Noémia de Sousa, ambos, militantes do Partido Comunista (SOUSA, 2014). Também fará parte do círculo intelectual formado em torno da Casa do Império o poeta Nicolás Guillén. Esses escritores, artistas e intelectuais de esquerda passam a integrar uma rede de relações sociais importante na ampliação do público leitor e admirador, um circuito bem sucedido na disseminação das produções literárias e artísticas.

Com essa interlocução, os laços de amizade se estreitam, favorecendo o trânsito em diferentes países. São notórias as declarações de alguns escritores de países africanos de língua portuguesa acerca da importância dos modernistas brasileiros, a exemplo de Jorge Amado e Graciliano Ramos, na construção de uma literatura nacional no continente africano. Desse modo, impõe-se considerar a militância e o engajamento político como potência na formação de um público à época. Ainda no ensaio O que é literatura?, Jean-Paul Sartre (2004) afirma que o escritor engajado é aquele que "abandonou o sonho impossível de fazer uma pintura imparcial da sociedade e da condição humana" (SARTRE, 2004, p. 28), e isso não significa aprisionamento partidário.

No entanto, no exercício de liberdade, o escritor não pode prescindir de um compromisso: abandonar a ideia de "universalidade abstrata" para alcançar uma "universalidade concreta". "Por universalidade concreta é necessário entender, pelo contrário, a totalidade dos homens que vivem em determinada sociedade" (SARTRE, 2004, p. 193). Nesse ensaio, Sartre faz uma crítica ao ideal cultuado, à época, da arte pela arte, enfim, da arte sem finalidade, de inclinação metafísica, ao tempo em que questiona o afastamento do escritor da comunidade leitora, isolado na torre de marfim. Amado, Neruda e Guillén têm em mira essa dimensão do engajamento, como exercício 
de liberdade, a despeito de seus vínculos partidários, a qual só terá sentido pela partilha com os leitores. Por isso, fazem da literatura uma via para a revolução social, pela ação das palavras, em um contexto fortemente marcado por ditaduras e movimentos fascistas.

Em 1948, Neruda tem o seu mandato de senador cassado pelo ditador Videla. Amado, também, quando é anulado o seu mandato de deputado após o cancelamento do registro do Partido Comunista, partindo para o exílio voluntário. Com a ditadura de Fulgencio Batista, Guillén considerou insustentável a sua permanência em Cuba, retornando à ilha após a revolução cubana. Assim, nos anos 1950, esses escritores vivem uma experiência do exílio na Europa, período em que se intensifica a repressão aos comunistas de países latino-americanos, os quais vão se refugiar na França. Passam a integrar um círculo de amizade com artistas e intelectuais renomados, a exemplo de Jean-Paul Sartre, Pablo Picasso e Ana Seghers. Juntos, realizam algumas viagens, no contexto de guerra fria, a países do Leste Europeu, União Soviética, China, Mongólia, como participam de congressos de intelectuais pela paz.Em 1951, Jorge Amado, que era membro do Bureau do Conselho Mundial da Paz, recebe o Prêmio Internacional Stalin da Paz em Moscou, o Nobel dos países socialistas. Em 1953, é a vez de Pablo Neruda, e Nicolás Guillén recebe o mesmo Prêmio em 1954.

O período do exílio está marcado ainda pela presença desses escritores, e de tantos outros, na América Latina, quando organizaram encontros, estabelecendo uma agenda que envolvia discussões sobre questões políticas, literárias e culturais, assegurando, assim, o contato com o público leitor e a divulgação de suas produções artísticas e literárias. Em 1953, Neruda organiza em Santiago do Chile o Congresso Continental de Cultura, de modo a reunir nomes de destaque da comunidade de artistas, escritores e intelectuais latino-americanos, dentre eles, Nicolás Guillén, Diego Rivera e Jorge Amado. Merece destaque a presença de Pablo Neruda no Brasil. Em 1945, quando ingressa no Partido Comunista do Chile, o poeta chileno lê para mais de 100 mil pessoas um poema dedicado a Prestes, no comício realizado em um estádio paulista de futebol, em homenagem a esse líder comunista, que fora anistiado depois de nove anos na prisão (cf. PRESTES, 2009).

O contato com o público seguramente demonstra o vigor da palavra cantada, da narrativa oral, sobretudo na América Latina, fortemente marcada pela cultura oral, a despeito da valorização da cultura letrada, que tem no registro escrito e no suporte livro a confirmação da erudição. Nos 1940, uma parcela significativa de público não tem acesso fácil ao livro - por questões econômicas ou escolaridade incipiente -, um bem cultural altamente prestigiado pela política cultural do Partido Comunista, no seu intuito de levar aos leitores a conscientização política. Portanto, o baixo grau de letramento vai contrastar com um ideal, o de ser culto, ainda hoje muito forte a despeito dos questionamentos.

Em seus estudos acerca do hibridismo cultural latinoamericano, Canclini chama atenção para a persistência da cultura letrada na América Latina:

Ser culto implica reprimir a dimensão visual em nossa relação perceptiva com o mundo e inscrever sua elaboração simbólica em um registro escrito. Temos na América Latina mais histórias da literatura que das artes visuais e musicais; e, é claro, mais sobre literatura das elites que sobre manifestações equivalentes das camadas populares (CANCLINI, 2014, p. 143).

Nesse sentido, não podem ser desprezadas nos estudos de recepção as estratégias das editoras, e de alguns escritores, ao fazerem edições de baixo custo, como fizeram Amado, Guillén e Neruda, visando alcançar um número maior de leitores, reduzir a "massa iletrada", quando o livro, em meio a jornais e revistas, não sofria alta concorrência com outros bens culturais e materiais. Na política cultural do Partido Comunista, disseminada através de diferentes programas e ações, residia a crença na revolução, que seria alcançada com o processo de letramento, o qual, sob a tutela do Partido e do Estado. O controle burocrático exercido por Stálin sobre a cultura levou León Trotsky (cf. TROTSKY, 2007) a tecer-lhe duras críticas no livro Literatura e revolução, escrito entre 1922 a 1923, por tolher a liberdade de criação. Se Stálin defendia uma cultura do proletariado, bolchevique, Trotsky reivindicava uma arte socialista, sem a marca da extração de classe.

$\mathrm{O}$ exílio de muitos intelectuais, escritores e artistas latino-americanos na Europa, em fins da década de 1940 a meados dos anos 1950, está marcado pela inserção deles no movimento comunista internacional, num alinhamento com a União Soviética, tendo como líder Stalin. Marcelo Ridenti (2011) destaca a aproximação entre Jorge Amado, Pablo Neruda e Nicolás Guillén, a partir do exílio na França. Segundo Ridenti (2011), nesse período forma-se uma rede de solidariedade entre os comunistas, e a imprensa comunista francesa os acolhe, divulgando suas produções. ${ }^{7}$ Os intelectuais comunistas criaram associações e sindicatos de escritores e artistas, promoveram inúmeros congressos e conferências mundiais pela paz nos países europeus, latino-americanos e em países do bloco soviético, em muitos dos quais os escritores tiveram seus livros traduzidos ${ }^{8}$.

\footnotetext{
Com a lei anticomunismo nos Estados Unidos, Jorge Amado é proibido de entrar nesse país em 1952, como também ficou proibida a circulação de seus livros.

8 Marcel Vejmelka(2014)destaca quea traduçãodos romances de JorgeAmado para o alemão tem início nos anos 1950, na RDA, a Alemanha Oriental, socialista, através de Ana Seghers, traduzidos das traduções francesas.
} 
Conforme Elena Beliakova (2014), em seu estudo sobre a recepção de Jorge Amado na Rússia, São Jorge dos Ilhéus foi o primeiro romance do escritor publicado na União Soviética, em 1948, seguido de Seara vermelha, em 1949, por editora estatal. Com uma popularidade extraordinária de público, Seara vermelha estava em todas as bibliotecas soviéticas da época, e o sucesso de Amado, tido como o maior escritor latino-americano para os russos, vai sendo mantido com as traduções dos novos romances. Segundo Beliakova, coube a Jorge Amado traduzir a literatura soviética nos anos 1940 e 1950, pela Editora Paz.

Na longa trajetória percorrida por Pablo Neruda, Nicolás Guillén e Jorge Amado, assiste-se a uma pluralidade de histórias, de narrativas tecidas em diálogo com uma comunidade interpretativa formada por fãs e leitores. São histórias que trazem diferentes modos de recepção de público, indicando inúmeros caminhos e possibilidades de trabalhos na escrita dessas histórias. Ao indagar sobre o tipo de narrativa a ser adotada em tal escrita, Peter Burke traz a seguinte provocação: "Parece que os historiadores teriam de desenvolver suas próprias "técnicas ficcionais' para suas 'obras factuais"' (BURKE, 1992, p. 341 $)^{9}$. Na escrita de histórias de literatura, essas técnicas podem ter como inspiração as narrativas da comunidade interpretativa, aberta a produções literárias que levaram ao questionamento relações de poder e que ainda alimentam um imaginário coletivo ávido por transformações, como são as produções de Neruda, Amado e Guillén. Não significa, com isso, exaltar a figura do intelectual que fala em nome do povo. Antes, contribui para confirmar a impossibilidade de se abdicar da dimensão reflexiva e criativa dos homens. Ao chegar até os leitores e leitoras, através de uma retórica eloquente, Neruda, Guillén e Amado confirmam a força da literatura, como um espaço de acolhimento e desassossego, de combate às injustiças sociais, em prol da revolução e da dignidade.

\section{Referências}

AMADO, Jorge. Navegação de cabotagem: apontamentos para um livro de memórias que jamais escreverei. 3. ed. São Paulo: Record, 1993.

BELIAKOVA, Elena. Jorge Amado e a literatura brasileira na Rússia. Amerika [Enligne], 10 | 2014, misenligne le 30 juin 2014. https://amerika.revues.org/4546. Acesso em: 03 mar. 2014.

BURKE, Peter. A história dos acontecimentos e o renascimento da narrativa . In:__. (Org.). A escrita da história; novas perspectivas. São Paulo: UNESP, 1992.

\footnotetext{
9 Burke destaca algumas produções criativas na escrita da história, ressaltando que a vertente historiográfica que investiu no estudo das micronarrativas tem sido bem-sucedida.
}

CANCLINI, Néstor García. Culturas hibridas: estratégias para sair e entrar na modernidade. 4. ed. Tradução Ana Regina Lessa, Heloísa Pezza e Gênese Andrade. São Paulo: Edusp, 2008

COMPAGNON, Antoine. O demônio da teoria: literatura e senso comum. Tradução de Cleonice Paes Barreto Mourão e Consuelo Fortes Santiago. Belo Horizonte: UFMG, 2001.

COSTA, Adriane Vidal. Pablo Neruda: uma poética engajada. Rio de Janeiro: E-books, 2007.

DELEUZE, Gilles; DELEUZE, Gilles. Crítica e clínica. Rio de Janeiro: Relume Dumará, 1997.

DUARTE, Geni Rosa. Invenções a muitas vozes: poesia, música e política em Nicolás Guillén. Antíteses, v. 4, n. 8, p. 849-872, jul./dez. 2011. Disponível em: <http://www.uel.br/revistas/uel/ index.php/antiteses>. Acesso em: 20 abr. 2017.

GODOY, Elena. A musicalidade em Nicolás Guillén. Revista Letras, Curitiba, n. 58, p. 137-145, jul./dez. 2002. Editora UFPR.

GUILLÉN, Nicolás. Paginas vueltas; memórias. Publisher, Unión de Escritores y Artistas de Cuba, 1982.

JAUSS, Hans Robert. A história literária como provocação à teoria literária. São Paulo: Ática, 1994.

MARGATO, Izabel; GOMES, Renato Cordeiro. O papel do intelectual hoje. Belo Horizonte: UFMG, 2004.

MIGNOLO, Walter. Histórias locais, projetos globais: colonialidade, saberes subalternos e pensamento liminar. Trad. Solange Ribeiro de Oliveira. Belo Horizonte: Editora da UFMG, 2003.

MOREIRA, Maria Eunice. História da literatura: algumas considerações teóricas. Revista Vidya, n. 37, jan./jun. 2002. $<$ https://www.periodicos.unifra.br/index.php/VIDYA/article/ view/471/457>. Acesso em: 05 abr. 2017.

NERUDA, Pablo. Confesso que vivi; memórias. Trad. Olga Savary. Rio de Janeiro: DIFEL, 1977.

OLINTO, Heidrun Kreiger. Histórias de literatura: conflitos e caminhos. Revista Légua \& Meia, UEFS, n., 1, 2002. Disponível em: <http://www2.uefs.br/ppgldc/revista1_35.html>.

ORTIZ, Victor Pérez Galdós. Los poemas de Nicolás Guillén dedicados al Che Guevara. Fuente: Libro Unhombre que actúa como piensa. Editora Pablo de laTorrienteBrau, 1998. Disponível em: <http://www.radiorebelde.cu/che/artes/che nicolas-guillen.html>. Acesso em: 03 mar. 2017.

PRESTES, Anita Leocádia. Luiz Carlos Prestes no comício do Pacaembu. Disponível em: <http://www.ilcp.org.br/ prestes/index.php?Itemid $=153 \& \mathrm{id}=48 \&$ option $=\mathrm{com}$ content\&view=article>. 2009. Acesso em: 20 jun. 2016.

RIDENTI, Marcelo. Jorge Amado e seus camaradas no círculo comunista internacional. Revista Sociologia \& Antropologia, Rio de Janeiro, v. 01, n. 02, p. 165-194, 2011. Disponível em: $<$ http://revistappgsa.ifcs.ufrj.br/wp-content/uploads/2015/ 03/8-ano1v2_artigo_marcelo-ridenti.pdf $>$. Acesso em: $18 \mathrm{dez}$ 2016.

RODRÍGUEZ RIVERA, G. Nicolás Guillén y el vanguardismo. Revista de Literatura Cubana, año 1, p. 59-70, 1982.

SARTRE, Jean-Paul. Que é a literatura? Trad. Carlos Felipe Moisés. São Paulo: Ática, 2004. 
SOUSA, Carla Maria Ferreira. Sob o signo da resistência: a poética de Noémia de Sousa no período de 1948-1951 em Moçambique. 2014. 110 fl. Dissertação (Mestrado em Estudo de Linguagens) - Universidade do Estado da Bahia, Salvador, 2014.

TROTSKI, Leon. Literatura e revolução. Trad. Luiz Alberto Moniz Bandeira. Rio de Janeiro: Zahar, 2007.

VEJMELKA, Marcel. Entre o exótico e o político: características da recepção e tradução de Jorge Amado na Alemanha. In: Amerika [Enligne], 10 | 2014, mis em ligne le 30 juin 2014.
Disponível em: <http://amerika.revues.org/4522>. Acesso em: 03 nov. 2016.

VÍDEO: Funeral de Pablo Neruda 1973. mp4. Disponível em: $<$ https://www.youtube.com/watch? $\mathrm{v}=\mathrm{xF} 7 \mathrm{~s} 8 \mathrm{CM}-\mathrm{dTY}>$. Acesso em: 01 mar. 2017.

Recebido: 07 de novembro de 2017

Aprovado: 29 novembro de 2017

Contato:marciasrios@terra.com.br (Márcia Rios da Silva) 